\title{
"NO PERMITA VUESTRA MAJESTAD QUE YO RECIBA DAÑO NI SE HAYA DE ACABAR EN MÍ ESTA CASA TAN BENEMÉRITA A SU REAL CORONA"1. ANNA CARAFA Y LA BÚSQUEDA DE UN MATRIMONIO PROVECHOSO (1624-1636)
}

\author{
Marina Perruca Gracia* \\ Universidad Rey Juan Carlos
}

\begin{abstract}
RESUMEN
El matrimonio de la heredera del principado de Stigliano y el ducado de Sabbioneta, Anna Carafa, supuso, además de un asunto familiar, una verdadera razón de Estado. La situación estratégica del feudo lombardo de Sabbioneta hizo que Felipe IV interviniese en las negociaciones para la elección de un candidato que defendiese los intereses de la Monarquía Hispánica, en contra de los propuestos por la familia Carafa. En medio de estas discusiones, el conde-duque, principal valedor del duque de Medina de las Torres hasta este momento, se mostró reticente tanto en su elección como cónyuge como en la concesión del virreinato napolitano, lo que pone en cuestión la hasta ahora aceptada hipótesis de que fue el valido el que motivó este enlace.
\end{abstract}

PALABRAS CLAVE: Felipe IV, Nápoles, nobleza italiana, Medina de las Torres, Carafa

*marina.perruca@urjc.es

1. Archivo General de Simancas (AGS), Estado, Nápoles, leg. 3332, doc. 5. Carta de Anna Caraffa a Felipe IV. Nápoles, 24 de mayo de 1633. 


\title{
"NO PERMITA VUESTRA MAJESTAD QUE YO RECIBA DAÑO NI SE HAYA DE ACABAR EN MÍ ESTA CASA TAN BENEMÉRITA A SU REAL CORONA". ANNA CARAFA AND THE QUEST FOR AN ADVANTAGEOUS MARRIAGE (1624-1636)
}

\author{
Marina Perruca Gracia* \\ Universidad Rey Juan Carlos
}

\begin{abstract}
The marriage of the heiress of the principality of Stigliano and the duchy of Sabbioneta, Anna Carafa, was, more than a family interest, a true reason of State. The strategic situation of the Lombard fief led Felipe IV to intervene in the negotiations for the election of a candidate to defend the interests of the Hispanic Monarchy, against those proposed by the Carafa's. In the midst of these discussions, the Count-Duke, main supporter of the Duke of Medina de las Torres to this moment, was reticent both in his election as spouse and in the granting of the Neapolitan viceroyalty, which calls into question the hitherto accepted hypothesis that it was the valid who motivated this union.
\end{abstract}

KEYWORDS: Philip IV, Naples, Italian nobility, Medina de las Torres, Carafa

*marina.perruca@urjc.es 
For Donna Isabella was a daughter of that Vespasian Gonzaga, one of the most illustrious men of his race. He fought in Africa, in Italy, and Flanders, for Charles V and Philip II and built Sabioneta, a castle in Lombardy surrounded by a few huts [...] after a long dispute about the fief of Gonzaga, Sabioneta only remained to Isabella; and even this only under Spanish tutelage ${ }^{1}$.

De la lectura de estas líneas, aparecidas en 1854 en la obra que Alfred von Reumont publicó sobre los Carafa de Maddaloni, se desprenden dos relevantes aspectos concernientes a esta familia ${ }^{2}$ : el primero de ellos es el significado del linaje familiar como premio a sus servicios en favor de los Habsburgos españoles; y el segundo, el valor de la fortaleza de Sabbioneta, situada en una zona estratégica de Lombardía, al norte de la península italiana.

Sendos aspectos jugaron un importante papel en las negociaciones para el matrimonio de la heredera de ambos linajes, Gonzaga y Carafa, Anna Carafa, princesa de Stigliano y duquesa de Sabbioneta, lo que la convertía en una de las mejores candidatas en el panorama italiano del momento. A pesar de que los linajes tuviesen origen en distintos territorios italianos, la Carafa que habría de unirlos nació en Nápoles, en la villa di Pietrabianca de Portici. Su destino, y el de su futuro marido, también se encontraron en el reino de Nápoles donde ambos dejaron una importante impronta y legado político, social y cultural.

1. A. von Reumont (1854), 223-224.

2. Este artículo se enmarca en el proyecto de investigación del Programa Estatal de Promoción al Talento y su Empleabilidad en I+D+i de la Agencia Estatal de Investigación (MINCINN), La Nápoles moderna (PEJ2018-004753-A). 


\section{LOS CARAFA, GONZAGA Y ALDOBRANDINI EN LA HERENCIA DE LA PRINCESA}

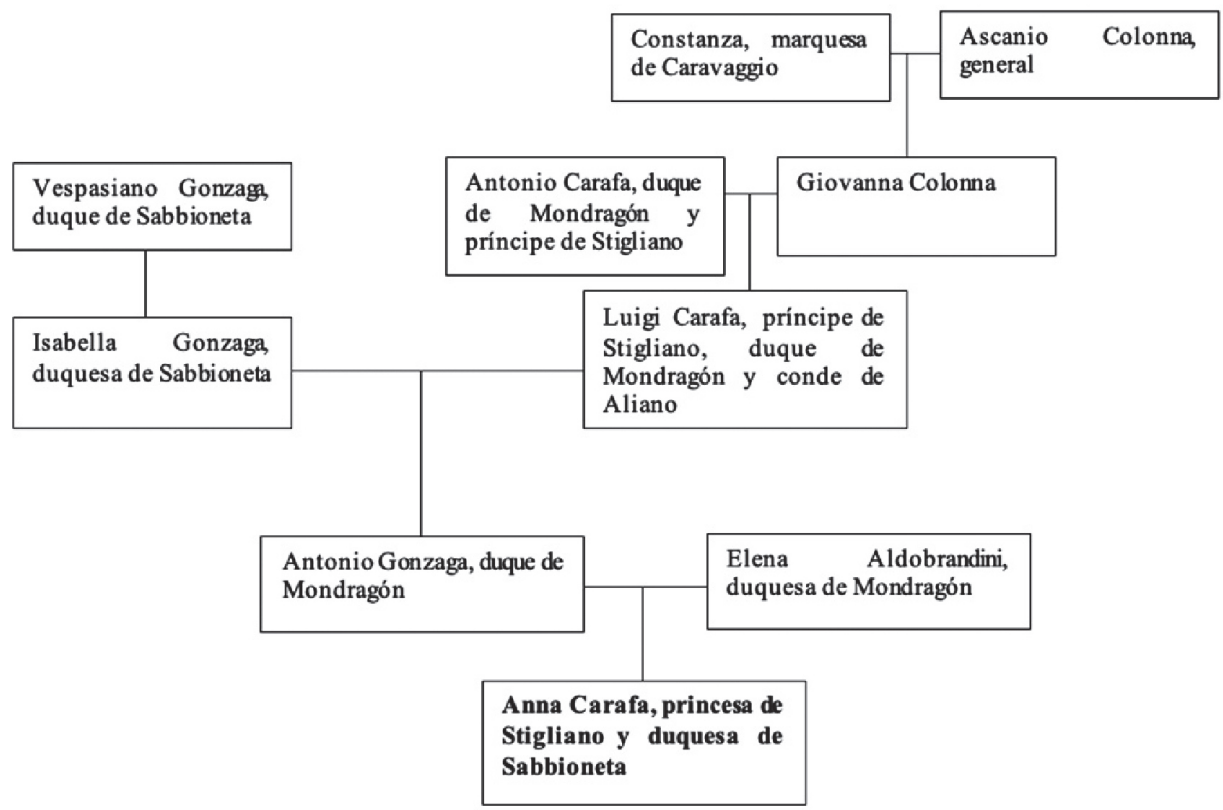

Árbol genealógico de Anna Carafa, princesa de Stigliano.

Fuente: Elaboración propia.

Isabella Gonzaga -única heredera de los títulos y feudos de su padre, Vespasiano Gonzaga ${ }^{3}$, impulsor de la fama de la familia- contrajo matrimonio con Luigi Carafa ${ }^{4}$, príncipe de Stigliano, duque de Mondragón y conde de Aliano. Quedaron así unidas dos de las más grandes familias italianas del momento en la persona del único hijo y, por ende, heredero de ambos, Antonio, quien a su vez casó con Elena Aldobrandini, sobrina del papa Clemente VIII y hermana de la duquesa de Parma ${ }^{5}$. De este matrimonio nacieron tres hijos, de los que únicamente sobrevivió una niña,

3. I. AfFó (1780).

4. Sobre la familia Carafa vide B. Aldimari (1691); S. Ammirato (1651), 139-159; B. Minichini (1860); M. Pisani (1992); G. Sabatini y F.C. Dandolo (2012); M. Visceglia (1988), 34-65.

5. R. VILLARI (2012), 457. 
Anna, que recibió una excepcional herencia compuesta no solamente por ilustres apellidos, sino también por numerosos títulos y feudos ${ }^{6}$.

La búsqueda de un matrimonio adecuado a su rango se convirtió, por tanto, en un asunto concerniente no solo a la familia, sino también a la propia Corona. Cuando Anna alcanzó la edad de contraer matrimonio, su madre y abuela todavía vivían, lo que causó que la sucesión de títulos y territorios, así como la elección del candidato, discurriese entre desavenencias no solo entre la familia y Felipe IV, sino dentro del seno familiar, especialmente entre Isabella Gonzaga y Elena Aldobrandini ${ }^{7}$.

A pesar de la importancia de esta noble napolitana por coincidir en ella la herencia de los Caraffa, Aldobrandini y Gonzaga, su figura no ha sido estudiada en profundidad todavía. El libro ottocentesco del inglés Horace Roscoe St. John ${ }^{8}$ se presenta, todavía hoy, como la obra más extensa dedicada a la princesa, si bien no puede considerarse la biografía definitiva, por estar repleta de opiniones y tópicos de la época que alejan a la obra de la validez propia de los ejercicios prosopográficos actuales, así como el artículo de Laura Lucci ${ }^{9}$ escrito pocos años después, aunque con importante valor documental. En los últimos años han aparecido algunos artículos dedicados a su persona, como los de A.E. Denunzio ${ }^{10}$ y V. Fiorelli ${ }^{11}$, que son, sin duda, punto de partida para su análisis; así como el capítulo que dedica R. Villari al matrimonio de la princesa ${ }^{12}$, en el que se llama la atención sobre algunos de los aspectos que se estudian en este artículo. Son importantes, además, los datos aportados por F. Bouza ${ }^{13}$ al descubrir la documentación del guardarobba de la princesa y su marido, el duque de Medina de las Torres, en el Archivo Histórico Nacional, que han permitido reconstruir buena parte de la colección pictórica del matrimonio, así como la tesis de F. Viceconte ${ }^{14}$ sobre el coleccionismo

6. A. Spagnoletti (1996), 29-32, 184, 190, y (2003). I. Enciso Alonso-Muñumer (2007), 271-275, 357-370, 380-385, 390, 402, 517, 565, 573-574, 599-600, 642, 653, 678, 785.

7. A. von Reumont (1854), 224.

8. H. R. ST. John, (1872).

9. L. LuCCI (1905).

10. A.E. Denunzio (2017) y (2012).

11. V. Fiorelli (2008).

12. R. Villari (2012), 456-476.

13. F. Bouza (2009).

14. Sobre el mecenazgo de los príncipes de Stigliano vide F. ViceConte (2013). En esta tesis la autora analizó parcialmente parte de la correspondencia de "las" Carafa-Aldobranidi en torno al matrimonio de la princesa Anna. 
del duque y las aportaciones de E. Sánchez García ${ }^{15}$ sobre el duque de Medina de las Torres.

Denunzio pone de relieve en sus aportaciones la importancia de la herencia recibida por Anna Carafa, así como la fuerte personalidad de la princesa abuela, verdadera gestora de los intereses familiares ${ }^{16}$, hecho que, como ya hemos apuntado, entró en conflicto con el carácter e inclinaciones de su nuera. La Corona se vio, de este modo, y como ya señaló A. Franganillo en el caso de la sucesión del principado de Stigliano, "negociando con mujeres"17. Asimismo, ambos autores reparan en la importancia de las negociaciones para el matrimonio de la princesa, cuya documentación he podido estudiar gracias a los fondos conservados en el Archivo General de Simancas principalmente.

Este trabajo no busca poner de relieve las estrategias o el poder de las nobles italianas como grupo social diferenciado, sino realizar un análisis de las estrategias de negociación que la Corona desarrolló con los linajes de los territorios extrapeninsulare ${ }^{18}$, que en este caso particular estuvieron representados por tres mujeres con distinta personalidad, influencia e intereses.

\section{CASAR A LA PRINCESA}

La cuestión del matrimonio de la heredera se retrotrae a una fecha tan temprana como 1624, año en el que murió su padre, el duque de Mondragón. Ante esta noticia, Felipe IV escribió al entonces virrey de Nápoles, Antonio Álvarez de Toledo, V duque de Alba:

habiéndose entendido que ha muerto el duque de Mondragón, me ha pareçido ordenaros digáis luego de mi parte a los príncipes de Stigliano que por ningún caso traten ni den oídos a plática ninguna que se les proponga para el casamiento de su nieta sin darme primero cuenta dello, y vos estaréis con cuidado de que esto se execute assí asegurándoles que siempre dessearé lo que fuere de mayor autoridad y bien suyo

Madrid a 18 de settiembre de 1624

yo el rey ${ }^{19}$.

15. E. Sánchez García (2017a) y (2017b).

16. A.E. Denunzio (2012), 189.

17. A. Franganillo (2019).

18. Sobre la nobleza napolitana en este tiempo vide G. Sodano (2018); G. Labrot (1979); (1995)

19. Archivo Ducal Casa de Alba (ADA), C.12-125. Carta de Felipe IV al virrey de Nápoles, duque de Alba. Madrid, 18 septiembre 1624, 
Anna Carafa contaba ya entonces con varios candidatos ${ }^{20}$ para desposarse. De acuerdo con Reumont, estos fueron, Taddeo Barberini, sobrino del papa Urbano VIII; "un Medici hermano de Fernando II archiduque de Austria", que no era sino Giovanni Carlo de Medici, hermano del gran duque de Toscana; "el duque de Módena, un príncipe polaco y Fernando de Toledo, condestable de Navarra, hijo del V duque de Alba"21. En la documentación aparece también el marqués de Castelvetere, hijo del príncipe de la Rochela y miembro de la casa Carafa, aunque se dice se le pidió "se apartase de proponer a la prinçesa de Sitllano"22.

Como ha estudiado A. Franganillo ${ }^{23}$ a través de la correspondencia florentina y veneciana, los candidatos de Mantua y Módena fueron Francesco I d'Este, nieto del conde de Módena, y Vincenzo II Gonzaga, duque de Mantua. El primero de los matrimonios fue acordado en 1625, si bien su padre, César d'Este, decidió romperlo en 1626 al no querer "ceder a la Monarquía Hispánica los derechos sobre Sabioneta"24. El segundo únicamente quedó en propuesta, ya que el mismo duque la desestimó, si bien R. Villari dice que se trató de un problema monetario, ya que el candidato veneciano no pagó los 400.000 ducados que se habían establecido en los acuerdos y que iban a destinarse a pagar algunas deudas de la casa de Stigliano ${ }^{25}$.

La proposición del matrimonio con el hijo del duque de Alba fue atajada en el mismo 1624, ya que al llegar el rumor a oídos del monarca este le escribió

quedo advertido y de la plática que se había movido algunos días antes de casarla con el condestable de navarra vuestro hijo y al mismo tiempo se me ha hecho aquí instancia para lo mismo en nombre del duque y príncipes de Módena para su hijo mayor, si bien se les ha respondido excussándome de tratar dello por estar introduçidas otras pláticas anticipadamente y no saber la voluntad del de Stillano, y assí se aguardará a ver lo que avisaré del fin que en esto tiene para que conforme a ello se trate de lo que mas convenga y vos estaréis con cuidado en esto supuesto la consideración que se debe tener

20. A. Franganillo añade la posible sugerencia al VII duque de Braganza para su hijo, el futuro Juan IV de Portugal si bien esta opción se descartó rápidamente. A. Franganillo (2019), 226.

21. A. von Reumont (1854), 224.

22. AGS, Estado, Nápoles, leg. 3332, doc. 3. La junta sobre el casamiento de doña Ana Carrafa. Madrid, 7 octubre 1633.

23. A. Franganillo (2019).

24. Ibidem, 225.

25. R. Villari (2012), 461. 
con los deudos de la casa y saber la voluntad de los padres, de S. Lorenço a 29 de octubre 1624 .

yo el rey ${ }^{26}$.

Unas semanas más tarde, en una nueva carta, Felipe IV le insistía a Alba en que no podía casarse la princesa sin el consentimiento regio, ni siquiera con su hijo. Asimismo, hacía que advirtiese a los abuelos "para que no dispussiesen de su nieta y subçesora sin licençia mía"27, a pesar de lo cual la búsqueda de un candidato no cesó. Las negociaciones estuvieron gestionadas por su abuela, la princesa de Stigliano, y su madre, la duquesa de Mondragón, ya que su abuelo vivía en un convento de Jesuitas desde la muerte de su nieto -acaecida en una fecha que no se especifica- y hasta su propio fallecimiento el 13 de enero de $1630^{28}$.

Cuando se hubieron descartado los candidatos mencionados anteriormente, los dos con más posibilidades eran Giovanni Carlo de Medici, hermano del gran duque de Toscana, y el primo de la princesa, Scipione Gonzaga, príncipe de Bozzolo. Sobre el candidato toscano, Franganillo subraya la recurrente aparición en las fuentes de esta propuesta a partir de $1628^{29}$. Intercedieron por él su madre, la archiduquesa María Magdalena de Austria, "su más férrea defensora", que pidió incluso la mediación de María de Austria, hermana de Felipe $\mathrm{IV}^{30}$, -que consiguió- y la del gran duque Fernando II, aunque sin éxito ${ }^{31}$.

En la documentación del Consejo de Italia encontramos que es en 1631 cuando "escribieron a su Majestad el gran duque de Toscana, la gran duquesa María Magdalena, las princesas de Stillano y duquesa de Mondragón, haciendo instancias para que su Majestad concediera el beneplácito para poderse casar el príncipe Juan Carlos"32, que, a diferencia de los Este, estos habían pagado en 1629, 700.000 ducados en favor de los Stigliano ${ }^{33}$.

26. ADA, C.12-126. Carta de Felipe IV al duque de Alba, virrey de Nápoles. San Lorenzo del Escorial, 29 octubre 1624.

27. ADA, C.12-128. Carta de Felipe IV al virrey de Nápoles, duque de Alba. Madrid, 8 noviembre 1624 .

28. Ibidem. A. von Reumont (1854), 224.

29. A. Franganillo, (2019), 227.

30. Ibidem, 227.

31. Ibidem, 228.

32. AGS, Estado Nápoles, leg. 3332, doc. 2. Documentación referente al matrimonio de D. a Ana Carrafa, princesa de Stigliano con D. Ramiro Núñez de Guzmán, duque de Medina de las Torres.

33. R. Villari (2012), 461. 
El Consejo de Estado pidió las opiniones de los duques de Alba y Alcalá, que pusieron de relieve los inconvenientes que causaría para la monarquía el matrimonio de esta princesa con el hermano del Gran Duque con relación a la posesión de la Sabbioneta, "que es una de las mas importantes de Italia assí para las cossas de Milán como para qualquier accidente que suceda en aquellas provincias" ${ }^{34}$. Tras consultarlo con $\mathrm{Fe}-$ lipe IV el 16 de octubre del mismo año, ordenó el consejo en carta del 25 de noviembre al conde de Monterrey, que dijese al Gran Duque que no se aprobaba el matrimonio. La decisión del monarca se debía a que el duque de Toscana "no se inclinaba a desmembrar su Estado", por lo que Sabbioneta dejaría de estar bajo la órbita española -ya que se trataba de un territorio dependiente directamente del Emperador ${ }^{35}-\mathrm{y}$ en el caso de que dejasen de ser aliados de España a causa de "los nuevos acçidentes" que pudieran "hacer mudar de opinión en el cual caso hallándose un hermano suyo tan poderoso de vassallos en el reino no fuera del real servicio de Vuestra Majestad"36.

En la carta a Monterrey, Felipe IV le decía que

en las condiciones particulares procurase desconcertar el negocio, juzgando acá, que el Gran Duque holgaría más de mostrar al mundo que él dejaba el negocio, que no el publicarse que su Majestad no lo consentía, y si para suavizarlo más fuesse conveniente el dar su Majestad intención de que ayudaría el casamiento del Gran Duque con una hija del Emperador ${ }^{37}$

A esto, además, añadía otras opciones en caso de que el matrimonio con la hija del emperador no saliese adelante. Una de ellas es que, "podría ser eclesiástico como habían hecho los hijos segundos de la casa de Florencia", a lo que el rey de España le ayudaría con una pensión de diez mil o doce mil ducados y su apoyo para el cardenalato. El Gran Duque aceptó la negativa del monarca hispano a pesar de su disconformidad con la misma, si bien a cambio pidió "de que haga alguna demostración con su casa como sería el occupar en algún cargo a alguno de sus hermanos". En consecuencia, se le ofreció el virreinato de Valencia al príncipe Juan

34. AGS, Estado, Nápoles, leg. 3332, doc. 3. La junta sobre el casamiento de doña Ana Carrafa. Madrid, 7 octubre 1633.

35. R. Villari (2012), 459.

36. Ibidem.

37. AGS, Estado Nápoles, leg. 3332, doc. 2. Relación de lo que ha pasado en el casamiento de la Princesa de Stigliano desde que se trató para el príncipe Juan Carlos. 
Carlos. El Consejo, por su parte, estableció que, debido a la joven edad del príncipe, se esperase "para de aquí a tres, o cuatro años".

De este modo el monarca establecía que quien debería casarse con Anna Carafa tenía que ser

en primer lugar de los parientes de aquella casa, en segundo con español y en tercero con qualquier otro vassallo de su Majestad de cualquier Reyno en la forma y con las condiciones q se había ordenado [...] atendiendo mucho a que lo tocante a la Plaça de Sabioneda quedasse lo mas favorable para su Majestad ${ }^{38}$.

Queda con ello patente que la importancia del matrimonio radicaba en el control de la plaza lombarda, la cual ganaría todavía más importancia a partir de 1635 con el comienzo del enfrentamiento hispano-francés en la guerra de los Treinta Años.

La encargada de transmitirles la noticia a las dos princesas de Stigliano y a la duquesa de Mondragón fue la virreina, condesa de Monterrey, que citó a las dos princesas de Stigliano y a la duquesa de Mondragón en el Palazzo Reale de Nápoles. Aunque Anna Carafa "mostraba mas inclinación a cumplir las órdenes de su Md, si bien temía mucho a su abuela", Isabella Gonzaga parecía decidida a casarla con el príncipe de Bozzolo ${ }^{39}$, su primo, y que si no conseguía el permiso para ello le entregaría la plaza de Sabbioneta a este. Además, amenazó a la propia Anna con enajenar todos sus bienes, por lo que la princesa pidió protección a Felipe IV a través del Colateral. A pesar de las amenazas, ni España ni la familia Carafa, -representada en sus distintas ramas por el duque de Maddaloni, el duque de Nochera y el hijo del príncipe de la Rochela-, estaban a favor de ninguno de estos candidatos, aduciendo cada uno distintas razones.

Empezó así una larga negociación para encontrar al candidato que cumpliese con los intereses de la Corona de España y de la familia Carafa. Para ello se creó, por orden de Felipe IV, una Junta para dirimir las cuestiones relativas al casamiento de la princesa de Stigliano. Esta se reunió por primera vez el 28 de septiembre de 1633 en la casa del arzobispo de Granada, Fernando de Valdés, gobernador del Consejo de Estado y presidente de esta,

\section{Ibidem.}

39. La intención de Isabella Gonzaga permanece hasta 1634 pues en carta del 21 de julio de ese año, escribe que el matrimonio debe realizarse con el príncipe de Bozzolo a causa de los problemas económicos que tienen. AGS, Estado, Nápoles, leg. 3332, doc. 69. Carta de la princesa de Stigliano Isabella Gonzaga, 21 de julio de 1634. 
y estaba formada por el marqués de Santa Cruz, el conde de la Puebla, el duque de Villahermosa y los regentes don Alonso de la Carrera, don José de Nápoles, don Esteban de Torrecilla y don Ferrante Brancha ${ }^{40}$. Hasta 1636, cuando se produjo el matrimonio entre la princesa y el duque de Medina de las Torres, esta junta discutió, primero, quién debía ser el candidato que debía desposarse con la noble napolitana y, después, las condiciones en las que se celebraría el matrimonio, es decir, las capitulaciones.

En la primera reunión se discutieron tres cartas enviadas a Felipe IV por la duquesa de Mondragón y las dos princesas de Stigliano tras el encuentro con los condes de Monterrey ${ }^{41}$. En la primera ${ }^{42}$, con el tono humilde que caracterizan las peticiones al monarca, Elena Aldobrandini recordaba a Felipe IV que hacía cuatro años que se estableció el matrimonio con el hermano del Gran Duque y pedía "mirar con ojos de piedad por la reputación y comodidad della [Anna] y del estado" y "que en semejante caso assí digno de compassión haya aconsolado dos mujeres viudas, y una hija innocente".

En la segunda de ellas, Anna Carafa, al igual que su madre, adoptaba también un tono respetuoso y le pedía al monarca "no hacerme perder la occasión, los años y la vida", porque se había empleado mucho tiempo en las negociaciones del matrimonio para recibir ahora la negativa real, ya que "todo el mundo tiene por echo el matrimonio". Asimismo, apelaba a su linaje, rogando "no permita Vuestra Majestad que yo reciba daño ni se haya de acabar en mí esta Casa tan benemérita a su Real Corona", y añadía, quizás de forma algo soberbia, "pues hace gracias y mercedes a todo el mundo y a mí sola me quiera negar esta, que por razón divina y humana se me debe en particular por hallarme menospreciada de todos" ${ }^{43}$. Sendas cartas fueron escritas el mismo día, 24 de mayo de 1633, y quizás por esto guarden similitudes en su estilo.

Por último, Isabella Gonzaga, que escribió la suya días antes, el 11 de mayo, comenzaba su airada misiva exponiendo cómo

me aconsolaba ver que tenía por patrón y señor un Rey tan justo y de santa intención que premia y remunera no solo a aquellos que fielmente le sirven

40. AGS, Estado, Nápoles, leg. 3332, doc. 3. La junta sobre el casamiento de doña Ana Carrafa. Madrid, 7 de octubre de 1633.

41. Ibidem, doc. 7. Carta del conde de Monterrey a Felipe IV. Nápoles, 2 de abril de 1633.

42. Ibidem, doc. 4. Carta de Elena Aldobrandini a Felipe IV. Nápoles, 24 de mayo de 1633.

43. Ibidem, doc. 5. Carta de Anna Caraffa a Felipe IV. Nápoles, 24 de mayo de 1633. 
pero aún a aquellos que poco o nunca le han servido, antes deservido en muchas occasiones y ahora parece que quiere que esta Casa tan fiel y leal a su Real corona se acaba, habiendo mis antepassados dado a VMagd el reyno de Nápoles y el estado de Milán ${ }^{44}$.

La duquesa de Mondragón continuaba con una enumeración de los servicios de la casa Carafa a la Corona de los reyes católicos y manifestaba que "en cambio de tan gran amor y servicio" recibían "tan buena paga que habemos caído y dado por Vuestra Majestad en manos y voluntad de los ministros de Vuestra Majestad y de los interessados que hacen de nosotras lo que les parece" 45 . Acusaba este cambio de parecer al por aquel entonces embajador en Roma, conde de Monterrey, subrayando los "malos tratamientos" que todo el mundo les hacía. Incluso, añadía, "derramamos lágrimas de sangre por el dolor tan grande que sentimos desto". Concluía relatando el prejuicio a su reputación, por haberse ya realizado los capítulos y existir cartas donde "se trata de esposa y retratos" e imploraba "por las llagas de Christo" a la piedad del monarca.

A causa de la actitud mostrada por Isabella Gonzaga a los condes de Monterrey y en su carta al rey, la Junta se mostró prudente en los primeros momentos, recordando la importancia de la familia Carafa, "tan numerosa y poderosa en aquella ciudad y Reyno", así como que la conservación de los reinos de la monarquía pasaba también por la "conservación de las familias dellos que han servido tanto" 4 . A esto se añadía que

visto y desengañados que no tienen parte en este casamiento serán el medio principal para que no se case con otra familia de aquel Reyno sino con el español que Vuestra Majestad mandase o del que pudiere venirles mas útiles a sus negocios y pretensiones.

El conde de Monterrey proponía que se les ofreciese, como primer candidato, uno de la propia casa Carafa con lo que el linaje estaría agradecido por este favor y, en segundo lugar, si la princesa "se alterase desta proposición con la casa fácilmente se encaminaría que venga a casarse con español", que parece que era la idea que más agradaba al monarca. Ferrante Brancha secundaba esta opinión.

44. Ibidem, doc. 6. Carta de Isabella Gonzaga a Felipe IV. Nápoles, 11 de mayo de 1633.

45. Ibidem.

46. Ibidem, doc. 3. La junta sobre el casamiento de doña Ana Carrafa. Madrid, 7 de octubre de 1633. 
Por su parte, Esteban de Torrecilla consideraba que "no hay causa de nuevo para alterar lo resuelto" y abogaba por que en las próximas comunicaciones a las princesas y duquesa de Mondragón se les insinuase que, si el matrimonio se efectuaba de acuerdo con las decisiones del monarca, la princesa sería recompensada con mercedes. Don José de Nápoles, con el mismo parecer, añadió que en casos como este no se trataba de quitar la libertad en el matrimonio sino "antes es mirar por el bien de los reynos". A continuación, sugería que se contestara a las cartas de Anna Carafa y su madre, pero que no se hiciera todavía a la de Isabella "que no ha escrito con la humildad que debía". Sin embargo, por ser ella la que "tiene toda la mano en este casamiento [...] convendrá ganar su voluntad", por lo que se debía mandar su carta al propio Monterrey y que este se la diera cuando conviniera.

Don Alonso de la Carrera, que compartía las consideraciones anteriores, estimaba que el matrimonio debía concertarse con español

siendo tan grandes los estados que posee y ha de heredar la princesa y de tan gran consequencia importa mucho q quien entra a goçarlos y sus desçendientes tengan tantas prendas y tan estrechos vínculos con esta corona que se tenga gran seguridad de que siempre se han de consultar en el servicio y devoción de Vuestra Majestad

En cualquier caso, la propuesta de que la nueva princesa de Stigliano casara con un miembro de la casa de los Carafa contribuía a tener "bien afecta" a sus miembros, aunque sabían que la abuela "le tiene odio muy antiguo y envejecido [a la casa Carafa]" y que entre ellos no se pondrían de acuerdo "porque ninguno ha de querer que otro le sea cabeza", lo cual terminaría por dar paso a la elección de un español. Incluso pensaron en que la princesa se casase en España "aunque sea haciéndole aventajar mercedes", estando todas estas maniobras encaminadas al mantenimiento de la plaza de Sabbioneta. De hecho, añade la Junta que "son estas señoras más francesas tanto más se debe procurar que case la princesa $\mathrm{D} .{ }^{\mathrm{a}}$ Ana con español para corregir y templar su ynclinación" ${ }^{47}$, si bien no hemos encontrado indicios de una posible alianza de esta rama de la familia con Francia, por lo que se trataría de un pretexto más para justificar el matrimonio con un español.

El conde de Monterrey comunicó al rey que el empeño por el matrimonio con el príncipe Juan Carlos se trataba por estar su casa "tan destruida y

\section{Ibidem.}


empeñada que no comen un real libre y antes lo van perdiendo todo"48. Don Alonso de la Carrera consideraba que la posibilidad de establecer matrimonios entre italianos y españoles era "parte de la grandeza de Vuestra Majestad", si bien sabemos que estos matrimonios solo se podían realizar bajo permiso del monarca. En cualquier caso, se mostró severo con el comportamiento altivo de Isabella Gonzaga, considerando que no se le debía responder, aunque sí a Anna Carafa y a su madre, como hemos apuntado con anterioridad.

El duque de Villahermosa, por su parte, declaró que era la primera vez que oía hablar de este asunto y que de acuerdo con lo sucedido ya no se volviera sobre los candidatos de la familia Carafa y en consecuencia abogaba por "pasar a tratar que sea español". El conde de la Puebla confesó que al principio de este asunto "entiende que hubo algún empeño desseando hacer merced al duque de Florencia", pero que mutó de opinión cuando los Consejos de Estado e Italia presentaron los inconvenientes, por lo que se sumaba a las opiniones anteriores. Asimismo, condenaba el tono de Isabella Gonzaga y el "desacordado estilo con que escribe".

El marqués de Santa Cruz hizo alusión a las ocasiones en las que los monarcas intervinieron en matrimonios de la nobleza, como en el caso de la duquesa de Aveiro, Juliana Lencastre, o la hija del marqués del Vasto, Isabel de Ávalos, afirmando "que los reyes nuestros señores en semejantes casos hacen oficios de Padres con sus vasallos"49. Por último, el arzobispo de Granada advirtió del peligro que podía suponer Isabella Gonzaga, sugiriendo se le transmitiera esto a Monterrey para que prestara "particular atención y cuidado".

En conclusión, dictaminaron "se proceda con blandura y suavidad" y "se les ofrezcan mercedes y comodidades pues a cualquier precio se podría comprar que estos estados siendo tan grandes no saliesen de vasallo de Vuestra Majestad que fuese español"50.

A continuación, se procedió a transmitir las decisiones de la Junta a las tres implicadas ${ }^{51}$, así como al conde de Monterrey $^{52}$.

Las siguientes cartas que se discuten en la Junta, con fecha de 20 y 28 de marzo y 1 de abril de 1634, ya hablan de la elección de duque

48. Ibidem, doc. 8. Carta del conde de Monterrey a Felipe IV. Nápoles, 3 de abril de 1633.

49. Ibidem, doc. 3. La junta sobre el casamiento de doña Ana Carrafa. Madrid, de 7 octubre de 1633.

50. Ibidem.

51. Ibidem, docs. 11-13. Cartas de Felipe IV a Isabella Gonzaga, Elena Aldobrandini y Anna Caraffa,

52. Ibidem, doc. 14. Carta de Felipe IV al conde de Monterrey. 
de Medina de las Torres. Fueron escritas por el príncipe de Bisignano ${ }^{53}$, el príncipe de Montenegro ${ }^{54}$, el duque de Nocera $^{55}$ y el príncipe de la Rochela $^{56}$, todos ellos de las distintas ramas de la familia Carafa, si bien las tres primeras estaban dirigidas a Felipe IV y la cuarta al conde-duque de Olivares.

En ellas manifestaban el buen servicio que se hacía al monarca con el matrimonio entre Anna Carafa y el noble español, aunque "conservándose el apellido de la cassa Carrafa en los hijos de este matrimonio" -apuntaban Bisignano y Nocera-, ya que de este modo "no quedará la casa agraviada si no muy favorecida de Vuestra Majestad". Parece, por tanto, que la decisión sobre el candidato estaba tomada, aunque aún tendrían que pasar dos años hasta que la boda tuviera lugar debido a las largas negociaciones entre la Junta, Isabella Gonzaga, Elena Aldobrandini, Anna Carafa y los representantes de las distintas ramas familiares.

\section{EL DUQUE DE MEDINA DE LAS TORRES Y LAS CAPITULACIONES MATRIMONIALES. EL PAPEL DE FELIPE IV Y EL CONDE-DUQUE (1634-1636)}

ha enviando la duquesa de Mondragón a un religioso para que proponga a Vuestra Majestad mi persona para este efecto, y aunque el sentimiento común ha sido siempre de que tiene muy particulares conveniencias del servicio de Vuestra Majestad el que este casamiento se haga con español y habiéndolo dejar no habrá ninguno que este más a los pies de Vuestra Majestad que yo ${ }^{57}$.

Desde que en Nápoles se supo la noticia hasta que en julio el duque de Medina de las Torres se dirigió a Felipe IV habían pasado siete meses. ¿Cómo se había negociado entonces su elección? La historiografía se encuentra dividida en torno a esta cuestión. De un lado, los clásicos opinan que fue

53. Ibidem, doc. 23. Carta de Tiberio Caraffa, príncipe de Bisignano traducida del italiano. Nápoles, 20 de marzo de 1634. En italiano, doc. 24.

54. Ibidem, doc. 21. Carta de Alfonso Caraffa, príncipe de Montenegro a Felipe IV. Nápoles, 28 de marzo de 1634.

55. Ibidem, doc. 25. Carta del duque de Nochera a Felipe IV. Nápoles, 1 de abril de 1634

56. Ibidem, doc. 22. Carta del príncipe de la Rochela al conde-duque, en italiano, Nápoles, 28 de marzo de 1634 ,

57. Ibidem, doc. 19. Carta del duque de Medina de las Torres a Felipe IV. Madrid, 16 de julio de 1634. 
el conde-duque quien favoreció este matrimonio. Así, A. Reumont ${ }^{58}$ afirma que fue el propio conde-duque quien le prometió el virreinato, hecho que causó la aceptación del matrimonio por parte de Anna y su madre. De la misma opinión es G. Marañón, que apunta que "le ayudó de tal modo que para conseguirlo, le dió el virreinato de Nápoles" 59 . Sin embargo, autores más recientes, como J. Elliott ${ }^{60}$, R.A. Stradling ${ }^{61}$, M. Herrero ${ }^{62}$, E. Sánchez ${ }^{63}$ y R. Villari ${ }^{64}$, hablan de que fue el propio monarca el que favoreció a Medina de las Torres para este matrimonio, lo que a la luz de las fuentes parece lo correcto. El propio Olivares manifestó el 13 de agosto de 1634

es mi confusión y dudas y esta crece al paso que va que se trata que este casamiento sea con el duque de Medina de las Torres porque el mundo ha de juzgar que esta sea acción enderezada por mí siendo la verdad que hoy es el día en que el duque no me ha hablado palabra ni hecho mas que escribirme un papel cuando escribió a Vuestra Majestad que no le he respondido ni al conde de Monterrey he escrito ni a otra persona del mundo ${ }^{65}$.

Además, la Junta, -en concreto Alonso de la Carrera que sabía la opinión del conde-duque-, dispuso

pues el conde duque sea sacrificado al servicio de Vuestra Majestad cuya mayor conveniencia pide que este cassamiento se effetúe debe llevar en paciencia las quejas que de su conclussión resultaren que son los frutos ordinarios del lugar que tan dignamente occupa y también se debe considerar que no es pequeña parte de la grandeza de Vuestra Majestad poder honrar a los que le sirven y assisten con tanto amor y fineça como el Duque de Medina de las Torres ${ }^{66}$.

Elliott habla de "un distanciamiento parcial de su propio yerno" 67 en este momento, por lo que el matrimonio con Anna Carafa sería la vía de

58. A. von Reumont (1854), 225.

59. G. MARAÑóN (1958), 185.

60. J.H. ElLiott (2004), 530-531 y 615 .

61. R.A. StradLing (1988), 112-117.

62. M. Herrero SÁnchez (s. a.).

63. E. Sánchez García (2017b).

64. R. Villari (2012), 467.

65. AGS, Estado, Nápoles, leg. 3332, docs. 57 y 151. Carta del conde-duque de Olivares a Felipe IV, Madrid, 13 de agosto de 1634.

66. Ibidem, doc. 65. Voto de D. Alonso de la Carrera. Madrid, agosto de 1634.

67. J.H. Elliott (2004), 530. 
escape para la "independencia" de Medina de las Torres del conde-duque. R. Villari, por su parte, afirma que este matrimonio era "l'occasione, se non propio l'origine, del contrasto tra Olivares e Medina" 68 .

El propio conde-duque sugirió a Felipe IV "que averigue esto", es decir, qué o quién motivó al conde de Monterrey a proponer al duque de Medina de las Torres para este matrimonio. Insta al rey a que "pida quenta al conde de Monterrey de porque hizo esto y si tuvo para esto orden de Vuestra Majestad o intención suya o de algún ministro o otra persona" ${ }^{69}$. También se muestra disgustado porque él había fundado una casa "en el duque en que dice se ajustaba conmigo" y que con esto "no sé como ha de ser possible ajustarlo"70.

El escenario había cambiado también en Nápoles, ya que las princesas de Stigliano estaban enfrentadas en torno a la elección de Medina de las Torres. Anna Carafa y su madre escribieron al monarca el 17 abril sendas cartas en las que avisaban del viaje del padre fray Juan de Nápoles "para que cerca de esto represente a Vuestra Majestad nuestros más verdaderos sentimientos" "71 y en las que le pedían que no se demorara ya que la princesa tenía una "edad" y las necesidades de su casa lo requerían ${ }^{72}$. Asimismo, exponían los desencuentros con la abuela, por lo que pedían protección, ya que la heredera de los Carafa "está en peligro de recibir gran daño de sus acciones". Si bien expresaban que las amenazas "no la han atemorizado", sino que ellas daban por hecho que el candidato presentado por el conde de Monterrey era el que el monarca había elegido. El 26 de abril, el cardenal Aldobrandini, hermano de la duquesa de Mondragón, escribe desde Roma para avisar también del envío de fray Juan de Nápoles para tratar el matrimonio ${ }^{73}$, de lo que se deduce que este miembro de la familia también aprobaba al candidato.

La misiva de la abuela de la joven princesa de Stigliano no tardaría en llegar, y el 24 de mayo escribió avisando de que "su nuera ha mandado al

68. R. Villari (2012), 456.

69. AGS, Estado, Nápoles, leg. 3332, docs. 57 y 151. Carta del conde-duque de Olivares a Felipe IV. Madrid, 13 de agosto de 1634.

70. Ibidem.

71. Ibidem, doc. 28. Carta de la duquesa de Mondragón a Felipe IV. Nápoles, 17 de abril de 1634. En italiano, doc. 29.

72. Ibidem, doc. 26. Carta de la princesa de Stigliano (Anna) a Felipe IV. Nápoles, 17 de abril de 1634. En italiano, doc. 27.

73. Ibidem, doc. 30. Carta del cardenal Aldobrandino a Felipe IV. Roma, 26 de abril de 1634. En italiano, doc. 31. 
padre Juan de Nápoles para casar a su nieta sin su permiso con el duque de Matalón" - en italiano Maddaloni- Diomede Pacheco y $\mathrm{Carafa}^{74}$, del que hasta ahora no se había hecho mención, por lo que existe la posibilidad de que se produjera un enfrentamiento entre los candidatos de la casa Carafa, pero que finalmente nunca se llegara a plantear al monarca como una opción efectiva.

Estas cartas debieron llegar a la Secretaría del Despacho Universal porque Jerónimo de Villanueva escribió al arzobispo de Granada, presidente de la Junta ${ }^{75}$, el 15 de julio para decirle que se resolviese el asunto del matrimonio de acuerdo con la correspondencia recibida. Dos días más tarde, el 17, y por orden del mismo arzobispo, el duque de Alburquerque fue nombrado miembro de la Junta a la que le comunicó "procuraré esforzarme para ir a su cassa de VSS mañana martes a las 5 de la tarde y assí podrá VSS convocar a los demás señores"76.

La reunión hubo de producirse una semana después, ya que Pedro de Arce el 23 de julio escribió diciendo que venía de Palacio y que no sabía cuándo podía ir a por el voto del duque de Alba, ya que este se levantaba a las doce y la Junta era a las cinco de la tarde y no sabía si llegaría a tiempo ${ }^{77}$. En la Junta iban a discutirse las cartas que llegaron con fray Juan de Nápoles el 14 de julio, por lo que se mandó aglutinar toda la documentación referente al caso $^{78}$.

Un documento recoge la exposición de los pareceres y las peticiones realizadas por fray Juan de Nápoles con relación al matrimonio de Anna Carafa con el duque de Medina de las Torres. En primer lugar, es importante señalar que no hay sospechas de que Anna y su madre quisieran proponer un candidato distinto al duque, como había querido insinuar Isabella Gonzaga. Explicaban que, efectivamente, fue el conde de Monterrey quien propuso al candidato que el rey quería. Sin embargo, por ser una de las causas del rechazo de otros candidatos que estos no fuesen fieles vasallos del rey Católico, continuaba, "se debe atender aquella razón de estado que siempre

74. Diomede Pacheco y Caraffa fue favorable a Medina de las Torres durante su virreinato y sería, años después, uno de los defensores de la monarquía española durante la revuelta de Masaniello. Sobre esta cuestión vide P. A. de TARSIA (1670), 148-153.

75. AGS, Estado, Nápoles, leg. 3332, doc. 34. Carta de Jerónimo de Villanueva al arzobispo de Granada. Madrid, 15 de julio de 1634.

76. Ibidem, doc. 36. Carta del duque de Alburquerque al arzobispo de Granada. Madrid, 17 de julio de 1634 .

77. Ibidem, doc. 41. Carta de Pedro de Arce. Madrid, 23 de julio de 1634.

78. Ibidem, doc. 44. Carta del arzobispo de Granada. Madrid, julio de 1634. 
platicaban los franceses en Nápoles, diciendo que convenía se juntassen siempre los vassallos desviados con personajes muy cercanos"79, aunque, como ya hemos apuntado, aceptaban al candidato oficial.

El franciscano también recordó en su intervención el beneficio que supondría para la Corona el que la plaza de Sabbioneta cayera en manos de Medina, consiguiendo de este modo lo que los monarcas españoles, dice "ha pretendido diversas veces", ya que anteriormente ha ofrecido "una ciudad de mucha importancia y a dinero hasta la suma de 800M". Una vez hubo manifestado en qué forma Anna Carafa servía a la Corona con este matrimonio enumeró las peticiones que hacían para, por fin, cerrar los acuerdos matrimoniales. La primera de ellas consistía en protección para la princesa, principalmente frente a su abuela "a fin que no reciba daño por este acto de obediencia a las reales órdenes", pero también protección en la plaza lombarda. La segunda petición consistía en la concesión del título de castellano de Castilnuovo para el duque de Medina de las Torres, para él "y otras cuatro vidas", al igual que, se dice, se concedió a Dña. María de Alarcón y sus hijos ${ }^{80}$.

La tercera, en relación con la anterior, era el oficio de gran justiciero, uno de los Sette Uffici del reino de Nápoles. Lo pedía para el duque, y cuatro vidas más, tal y como se concedió el de Gran Almirante al duque de Sessa el siglo anterior. Ambos títulos, carentes de poder fáctico, pero sí simbólico, eran de carácter regnícola, por lo que con ellos se dotaría al cónyuge hispano del componente napolitano del que carecía. En cualquier caso, tampoco se deben obviar las rentas asociadas a la castellania de Castilnuovo por lo que, aunque el simbolismo de los cargos, sobre todo el de gran justiciero, era muy fuerte, el factor económico resultaba también muy significativo. Este proceso de "hacer más napolitano" al duque pasaba también porque su residencia fuese Nápoles, que era, al fin, el lugar donde los Carafa podrían tenerle más cerca.

Esto no fue todo, ya que también pidieron el cargo más importante que un súbdito del rey podría tener en Nápoles, el de virrey. A fin de evitar una posible negativa del monarca por encontrarse este puesto ya ocupado,

79. Ibidem, doc. 46. Relación de las peticiones para el matrimonio de Anna Caraffa hechas por fray Juan de Nápoles en Madrid, julio de 1634. En italiano, doc. 45.

80. María de Alarcón y Mendoza, fue la sucesora de Fernando Pablo de Alarcón y Mendoza (o Hernando de Alarcón), capitán general de las armas del emperador y castellano de Castilnuovo. El 21 de febrero de 1526, Carlos V le otorgó el marquesado de Villasiciliana como premio a su labor en las campañas militares. A. SuÁrez de Alarcón y Mendoza (1665), 448-452. F. Marhuenda (2019), 288. 
proponían que "cuando esto no tuviesse hoy lugar por servicio de Vuestra Majestad podría passar a Sicilia con futura succesión de Nápoles", ya que el virreinato siciliano ocupaba una posición inferior en el cursus honorum de la administración hispánica frente al de Nápoles, considerado el más importante junto con la Embajada en Roma.

En esta línea, citaban algunos ejemplos de nobles que ocuparon distintos virreinatos, como el conde de Miranda, que primero fue virrey de Cataluña y después de Nápoles; el conde de Lemos ${ }^{81}$, virrey de Nápoles y luego de Sicilia; y el duque de Alcalá, que lo fue de Cataluña, Nápoles, Sicilia y, en fecha posterior al escrito, también gobernador de Milán. Añadía, asimismo, que "no debe obstar esto al duque tanto más que los parientes de doña Ana" -el duque de Maddaloni y el de Nocera-, "y los sobrinos del casamiento". Como sabemos, el duque de Nocera ${ }^{82}$ fue nombrado en 1639 virrey de Aragón y grande de España y, al año siguiente, virrey de Navarra, aunque es más probable que estas mercedes fueran fruto de sus servicios a la monarquía, concretamente su participación en la batalla de Nördlingen, al servicio del cardenal-infante en Flandes y como capitán general de Guipúzcoa, que por la petición de su sobrina años antes.

Las capitulaciones giraron en torno a estos cuatro puntos, a saber: protección, la castellania, el oficio de gran justiciero y el virreinato. Del resto de negociaciones propias de los matrimonios -denominadas "cosas domésticas"- se decía que "se discurría con el mismo duque"83. Quedaba así patente qué aspectos eran los realmente determinantes.

Las concesiones del monarca ante las peticiones, en una primera contestación ${ }^{84}$, fueron prudentes. En cuanto a la protección, "hásele dicho que $\mathrm{Su}$ Majestad toma en su protección a Doña Ana Carrafa". El virreinato, por contra, no se le concedía todavía, sino la embajada extraordinaria en Roma y "promessa de virrey de Náp[oles]". Sobre la castellania "se le advierte que no se le da futura successión de encomiendas, sino que el mismo día que haya de entrar a gozar del Castillo goce otra tanta renta en encomiendas effectivas", por vida del duque y dos más, en lugar de las cuatro que se pedían. Del oficio de gran justiciero no queda claro, pero en

81. El VIII conde de Lemos fue virrey de Sicilia e interino de Nápoles. El VI y VII condes solo lo fueron de Nápoles. I. Enciso Alonso-Muñumer (2007), 166-184.

82. Sobre el duque de Nocera, vide B. Croce (1995), 50-67.

83. AGS, Estado, Nápoles, leg. 3332, doc. 46. Relación de las peticiones para el matrimonio de Anna Caraffa hechas por fray Juan de Nápoles en Madrid, julio de 1634. En italiano, doc. 45 .

84. Ibidem, doc. 47. Respuesta de Felipe IV a fray Juan de Nápoles, julio de 1634. 
otro documento aparece que lo tiene en propiedad el marqués de Fuscaldo, que lo había adquirido por 50.000 ducados ${ }^{85}$.

Con estas resoluciones se decidió reunir la Junta el 30 de julio. En ella estuvieron presentes el arzobispo gobernador del Consejo, el cardenal Zapata, el inquisidor general, don Francisco Antonio de Alarcón y los regentes don Alonso de la Carrera, don José de Nápoles y don Ferrante Brancha. El gobernador del Consejo expresó a Felipe IV que el duque de Alba tendría "alguna differencia sobre los assientos o votar con el Cardenal Çapata o con el arzobispo inquisidor general [...] y ordeno que votasse en su posada". Pedro de Arce acudió a las casas del duque de Alba y de Alburquerque, este último indispuesto, y recogió allí sus votos. Durante la sesión se hizo un repaso de todo lo sucedido desde el intento de matrimonio con el príncipe Juan Carlos, cuya fecha de desestimación aparece en octubre de 1633. En esta reunión estuvo también presente fray Juan de Nápoles a fin de que dijera "todo lo que particularmente tuviere que representar”. Así, insistió en la concesión del cargo de virrey de Nápoles y en cuanto al oficio de gran justiciero, objetó que

se pone también en consideracion a Vuestra Majestad que cumple a su Real servicio que este officio se dé a español y honrrado de su real casa, pues es él que ha de proponer lo que se pide por parte de Vuestra Majestad en los Parlamentos Generales que aquí se llaman Cortes que si bien esta proposición pertenece al Gran Condestable, todavía por no vivir en el Reyno sino en Roma el proponer queda al Gran Justiciero q es el segundo voto, por todo lo qual es de parecer que Vuestra Majestad para q este matrimonio tenga effecto puede servirse de conceder al Duque lo que se pide remitiendo todo lo dicho a lo que pareciera a Vuestra Majestad que será lo más acertado.

Cierto es que los Sette Uffici participaban en los Parlamentos, si bien, como feudatario napolitano por su matrimonio con la princesa Anna, Medina de las Torres también entraba a formar parte de la plantilla de parlamentarios en las asambleas del Reino. El cargo de gran justiciero podía reforzar la autoridad del que lo portaba, aunque esta se fundamentaba en su cercanía al virrey o en la capacidad de crear redes clientelares que favorecieran sus intereses, como el resto de los nobles. En este sentido, cabe preguntarse si pedían este cargo para que defendiese los intereses del monarca o, en cambio, los del propio linaje de los Carafa.

85. Ibidem, doc. 51. Votos de la Junta sobre el casamiento de Anna Caraffa, 30 de julio de 1634. 
El rey contaba, por lo general, con vasallos poderosos que defendían los intereses de la Corona en los Parlamentos. El virrey, aunque árbitro de estos, también podía condicionar las opiniones de los regnícolas. El Parlamento era una forma más de expresión política donde el voto de una sola persona no iba a cambiar las resoluciones generales, ya que las decisiones que se tomaban en él no solo tenían lugar en las asambleas, sino principalmente, fuera de ellas. Se insistía en esta cuestión varias veces y se instaba a que se le otorgara el cargo una vez hubiera fallecido el marqués de Fuscaldo. Además de lo ya apuntado, el cargo llevaba asociada una renta de 2.300 ducados anuales, suma considerable. En esta ocasión rebajó las vidas por las que pedía el cargo, que serían la del duque y dos más. En cuanto a la castellania, también por tres vidas, "para hacer merced a la princesa que se ha puesto en las manos de Vuestra Majestad dexando los otros matrimonios". Solicitaba que, en caso de que no se pudiese dar el oficio de virrey para el cónyuge, "se pudiera desviar [esta proposición] dándola otras mercedes o las refferidas por más vidas, sería acertado porque quedaría el duque sirviendo a Vuestra Majestad en esta corte".

De esta forma se pone de manifiesto cómo una de las más importantes pretensiones por parte de los Carafa era que el duque de Medina residiera en Nápoles, por lo que los oficios y cargos que reclamaban para él debían ser lo suficientemente sugerentes para el noble español, tanto por sus rentas como por su prestigio social. De hecho, se indicaba que "la princessa no se ha de apartar de esta pretensión y que no ha de passar adelante la plática sin esta condición".

\subsection{La negociación}

Aquí comenzó una discusión en el curso de la cual se argumentó que, si la pretensión de los Carafa era que Medina de las Torres fuera virrey para residir en el reino de Nápoles, estos debían saber que una vez terminase su gobierno habría de marcharse porque "ni un día se dejan hallar en los reynos", por lo que este razonamiento no sería suficiente. Aún así, el valedor de las Carafa insistió y dispuso que

cuando obstinadamente porfiasse en lo del virreynato de Nápoles y no pudiesse concluirse de otra manera este negocio se podría Vuestra Majestad servir de condescender en ello, no sé limitando a cierto tiempo con que le quedaría a Vuestra Majestad campo para según las occassiones occurrente disponer lo que fuere más de su Real servicio. 
Se acordó que se comunicara este punto al cardenal Aldobrandini con el objetivo de transmitírselo él a su hermana y sobrina y "les dé a entender lo que les está bien" y que "Vuestra Majestad mirará al bien y mayor conveniencia de la Casa".

Los miembros de la Junta expusieron sus pareceres en torno a los cuatro puntos. Don Alonso de la Carrera expuso que el monarca estaba "en cierta manera obligado" a dar mercedes a la persona que se case con la princesa porque así se lo expresó el conde de Monterrey a las princesas de Stigliano y a la duquesa de Mondragón. La importancia de las posesiones de la princesa, "tres estados muy principales en el reyno de Nápoles, parte en las marinas, parte en los confines del dominio ecclesiástico, con ciudades y passos muy importantes", así como el futuro territorio de Sabbioneta, eran, de acuerdo con de la Carrera, motivo suficiente para que Felipe IV debiera "hacer todo esfuerço". Añadió que una vez "entrasse en poder del duque sería lo mismo que estar en el de Vuestra Majestad", lo que haría que en esos estados "reconoceran de la poderosa mano de Vuestra Majestad y es parte de grandeza que conozca el mundo cuán poderosos son los influjos de la gracia de Vuestra Majestad"86. El arzobispo Inquisidor General parecía menos condescendente y lo dejaba "a beneplácito de VMd". El cardenal Zapata, el arzobispo Gobernador, el duque de Alburquerque ${ }^{87}$ y el de Alba ${ }^{88}$ -estos últimos votaron aparte, desde sus casas- se mostraron de acuerdo con los demás, mientras que Zapata volvió a incidir en el hecho de que Medina debería abandonar el reino al terminar su virreinato. Por último, el arzobispo gobernador se mostró especialmente favorable a la concesión del título de virrey.

El conde-duque, como ya expusimos, que estaba completamente en contra de la concesión del título de virrey, también objetaba algo en cada uno de los puntos, de lo que se desprende cierta reticencia al matrimonio ${ }^{89}$. Sobre el virreinato, dice "tengo por punto de infinitos inconvenientes el hacerse esta merced a la casa de estillano". De la castellania, que los castillos debían darse a personas con experiencia en la defensa de este tipo de fortalezas, así que para no negarle también este punto, propone que se dé lo que valen las encomiendas asociadas a Castilnuovo porque él cree que

86. Ibidem.

87. Ibidem, doc. 52. Voto del duque de Alburquerque, 22 de julio de 1634.

88. Ibidem, doc. 53. Voto del duque de Alba.

89. Ibidem, docs. 57 y 151. Carta del conde-duque de Olivares a Felipe IV. Madrid, 13 de agosto de 1634 . 
el motivo que ha llevado a la casa de Stigliano a pedir esta merced no es el puesto en sí, sino las rentas que iban aparejadas al mismo. El oficio de gran justiciero "me parece que no tiene inconveniente grande". Incluso objeta la conveniencia de que Sabbioneta pase a manos del duque de Medina, punto en el que todos los miembros de la Junta se habían mostrado favorables desde el principio. Matiza que "es mayor el peligro de la indignación" al hacerle esta merced al duque, que es español, por lo que debería "pesar un poco si este empeño es mayor para Vuestra Majestad" $" 90$ al casarlo con un español o con un italiano.

Esto hizo que en las siguientes reuniones de la Junta, de $24^{91}$ y $31^{92}$ de agosto, sus miembros mutasen o se reafirmasen en las opiniones mostradas anteriormente. Así, el cardenal Zapata pareció estar de acuerdo con la opinión del conde-duque sobre las cuestiones del oficio de virrey, aunque don Alonso de la Carrera, como ya había manifestado, junto al arzobispo inquisidor general ${ }^{93}$ y don Antonio de Alarcón ${ }^{94}$, consideraron que aunque pudiera ser cierto que algunos pensasen que era el conde-duque el que hubiera motivado el matrimonio, no debían ahora echarse por tierra todas las negociaciones sino que aún así se efectuase el matrimonio. Es decir, que aunque estaban de acuerdo con él, declaraban, no cambiarían su opinión. Don Alonso de la Carrera fue más allá y expresó claramente su parecer contrario a la concesión de la embajada de Roma, por haber ya cuatro embajadores allí y ser un aumento del gasto innecesario ${ }^{95}$.

Los regentes José de Nápoles y Ferrante Brancha, que hasta ahora no habían votado, también lo hicieron en las dos juntas. El primero se hace eco en su declaración de los problemas económicos de la familia, lo que podría derivar en dificultades para Medina de las Torres, para que tuviesen esto en cuenta ${ }^{96}$. Ferrante Brancha, por su parte, defendió la candidatura y las mercedes para Medina, en contra de la opinión del conde-duque. Aduce que, aunque las razones del conde-duque puedan ser pertinentes al tratarse de "un vassallo y criado de la cualidad del duque de Medina de las Torres", y para un matrimonio que traerá tanto beneficio a la monarquía, "más se

90. Ibidem.

91. Ibidem, doc. 68. Reunión de la Junta, 24 de agosto de 1634.

92. Ibidem, doc. 58. Reunión de la Junta, 31 de agosto de 1634.

93. Ibidem, doc. 63. Voto del arzobispo inquisidor general.

94. Ibidem, doc. 64. Voto de D. Antonio de Alarcón.

95. Ibidem, doc. 65. Voto de D. Alonso de la Carrera.

96. Ibidem, doc. 72. Voto del regente José de Nápoles. 
ha de atender a que esto se consiga que a las circunstancias que en otro caso podrían difficultar la concessión dellas"97.

Se reunieron de nuevo el 28 de septiembre ${ }^{98}$, aunque sin avanzar en el asunto ya que se volvió a rememorar la cuestión desde el principio sin alcanzar nuevas conclusiones. Sin embargo, unos días más tarde, llegó, por fin, la decisión de la Junta, a 1 de octubre de $1634^{99}$. Esta fue aceptar el punto de la protección del estado de Sabbioneta, que el oficio de gran justiciero (tabla 1) y castellano ${ }^{100}$ fuese por tres vidas, la del duque y dos más para sus descendientes, y remitían al rey la relación de los votos (tabla 2) en cuanto al oficio de virrey, ya que, como se observa, no estuvieron de acuerdo.

Tabla 1. Votos para el oficio de gran justiciero

\begin{tabular}{|c|c|c|}
\hline & Primera consulta & Segunda consulta \\
\hline Duque de Alba & $\begin{array}{l}\text { Que le juzga por digno del puesto } \\
\text { cuando haya vacado por el marqués de } \\
\text { Fuscaldo. }\end{array}$ & Lo mismo. \\
\hline $\begin{array}{l}\text { Duque DE } \\
\text { Alburquerque }\end{array}$ & $\begin{array}{l}\text { Que se puede esperar siempre de las } \\
\text { reales manos de su Majestad se le haga } \\
\text { esta merced como se pide. }\end{array}$ & Idem \\
\hline Regente Brancha & $\begin{array}{l}\text { Que se conceda por la vida del duque y } \\
\text { otras quatro como se pide. }\end{array}$ & A lo votado. \\
\hline $\begin{array}{l}\text { DON JosEPH DE } \\
\text { NÁPOLES }\end{array}$ & $\begin{array}{l}\text { Por tres vidas una del duque y dos } \\
\text { descendientes suyos. }\end{array}$ & A lo votado. \\
\hline $\begin{array}{l}\text { DON Alonso DE LA } \\
\text { CARRERA }\end{array}$ & $\begin{array}{l}\text { Por la vida del duque y otras dos de } \\
\text { descendientes suyos deste matrimonio. }\end{array}$ & $\begin{array}{l}\text { Que si para concluir este } \\
\text { matrimonio fuera menester } \\
\text { conceder una vida más deste } \\
\text { officio se haga. }\end{array}$ \\
\hline $\begin{array}{l}\text { DON Francisco } \\
\text { AnTONIO de ALARCÓN }\end{array}$ & $\begin{array}{l}\text { Por la vida del duque y otras dos } \\
\text { descendientes suyos deste matrimonio. }\end{array}$ & A lo votado. \\
\hline
\end{tabular}

97. Ibidem, doc. 67. Voto del regente Ferrante Brancha.

98. Ibidem, doc. 76. Reunión de la Junta a 28 de septiembre de 1634.

99. Ibidem, doc. 80. La junta sobre el casamiento de doña Ana Carrafa. Madrid, 1 de octubre de 1634.

100. En este punto se precisa que "no se le da futura succesion de encomiendas, sino que el mismo dia que aya de entrar a gozar del castillo goze otra tanta quantidad de encomienda effectivas donde no el castillo". AGS, Estado, Nápoles, leg. 3332, doc. 88. 


\begin{tabular}{|c|c|c|}
\hline & Primera consulta & SEGUNDA CONSULTA \\
\hline $\begin{array}{l}\text { EL ARZOBISPO } \\
\text { INQUISIDOR GENERAL }\end{array}$ & $\begin{array}{l}\text { Con la mayor parte de la junta y } \\
\text { que por poco más o menos no se } \\
\text { desconcierte el casamiento y que las } \\
\text { dos vidas despues de la del que sean } \\
\text { de descendientes deste matrimonio. }\end{array}$ & \\
\hline EL CARDENAL ZAPATA & $\begin{array}{l}\text { Para la vida del duque y otras dos de } \\
\text { descendientes deste matrimonio. }\end{array}$ & \\
\hline $\begin{array}{l}\text { EL GOBERNADOR DEL } \\
\text { CONSEJO }\end{array}$ & $\begin{array}{l}\text { Por la vida del duque y otras quatro } \\
\text { para hijos y descendientes deste } \\
\text { matrimonio. }\end{array}$ & \\
\hline EL CONDE-DUQUE & $\begin{array}{l}\text { Que no le parece tiene inconveniente } \\
\text { el concedérselo por alguna vida o } \\
\text { vidas como se consulta. }\end{array}$ & \\
\hline
\end{tabular}

Fuente: Elaboración propia a partir de Regulación de los votos de las consultas sobre el casamiento de la princesa de Stillano en lo del officio del gran justiciero.

AGS, Estado, Nápoles, leg. 3332, doc. 77.

Tabla 2. Votos para el cargo de virrey

\begin{tabular}{|c|c|c|}
\hline & Primera consulta & SEgUNDA CONSULTA \\
\hline REgente Brancha & $\begin{array}{l}\text { Virrey de sicilia con futura successión } \\
\text { de Nápoles. }\end{array}$ & Lo que tiene votado. \\
\hline $\begin{array}{l}\text { DON JOSEPH DE } \\
\text { NAPOLES }\end{array}$ & $\begin{array}{l}\text { Pues de embaxador y promessa de } \\
\text { gobierno de Nápoles o Siclia. }\end{array}$ & Lo mismo. \\
\hline $\begin{array}{l}\text { Don Alonso de la } \\
\text { CARRERA }\end{array}$ & $\begin{array}{l}\text { Promesa de uno de los virreynatos de } \\
\text { Nápoles o Siclia declarando la merced } \\
\text { antes de su partida y si instaren por lo } \\
\text { de náp[ole]s se podría condescender } \\
\text { con ello no se limitando a cierto } \\
\text { tiempo. }\end{array}$ & $\begin{array}{l}\text { Remitese a lo que tiene vota- } \\
\text { do. }\end{array}$ \\
\hline $\begin{array}{l}\text { Don Francisco } \\
\text { Antonio de Alarcon }\end{array}$ & $\begin{array}{l}\text { Offerta del virreynato de Nápoles } \\
\text { reservando el cumplimiento a la } \\
\text { voluntad de su Majestad. }\end{array}$ & Idem \\
\hline $\begin{array}{l}\text { El ARZOBISPo } \\
\text { INQUISIDOR GENERAL }\end{array}$ & $\begin{array}{l}\text { Que la futura successión de Nápoles } \\
\text { no sea immediantamente ahora sino a } \\
\text { beneplácito de su Majestad. }\end{array}$ & $\begin{array}{l}\text { Que se disponga de manera } \\
\text { que se les dé satisfacción. }\end{array}$ \\
\hline
\end{tabular}




\begin{tabular}{|c|c|c|}
\hline & Primera consulta & SEGUNDA CONSULTA \\
\hline El Cardenal Zapata & $\begin{array}{l}\text { Que porque no podrá quedar en } \\
\text { Nápoles después de acabado el } \\
\text { gobierno se considere q sea más del } \\
\text { servicio de su Majestad. }\end{array}$ & $\begin{array}{l}\text { Lo que propone el conde- } \\
\text { duque y que le tiene por } \\
\text { apropósito para qulquier } \\
\text { grande de officio y gobierno. }\end{array}$ \\
\hline $\begin{array}{l}\text { EL GoBERnADOR DEL } \\
\text { CONSEJO }\end{array}$ & $\begin{array}{l}\text { Que se le offresca luego el de Sicilia } \\
\text { pra quando vacare y el de Nápoles no } \\
\text { habiendo inconveniente. }\end{array}$ & \\
\hline EL CONDE-DUQUE & $\begin{array}{l}\text { Embaxada extraordinaria a Roma } \\
\text { y cédula de Virrey de Nápoles a } \\
\text { voluntad de su Majestad sin señalar } \\
\text { ningún tiempo. }\end{array}$ & \\
\hline
\end{tabular}

Fuente: Elaboración propia a partir de Regulación de los votos de las consultas sobre el casamiento de la princesa de Stillano en lo del cargo de Virrey. AGS, leg. 3332, doc. 79.

El día 11 de octubre se reunió Pedro de Arze con el padre fray Juan de Nápoles para "ajustar los cabos contenidos en el papel"101. El 26 el rey respondió a la Junta diciendo que todo estaba resuelto, que si faltase algo le consultasen todos pero que no "embaracen" con tantas consultas. Señalaba algunas cuestiones que deberían rectificarse en el acuerdo, la primera que se diga expresamente que el feudo de Sabbioneta está entre la protección que le da el rey a Anna Carafa, porque solo se nombra la palabra estados, con carácter general. Segundo, que se añadiese "futura successión por complacer a las princesas" en la cuestión del cargo de virrey. Tercero, sobre el oficio de castellano, "se declare que en llegando el caso de la vacante del castillo, pueda entrar él a gastale y que si se le dieren las encomiendas immediantamente en la concurrente cantidad de la que valiere el castillo dejará el castillo"102.

El 11 de diciembre se acordó escribir a las dos princesas y a la duquesa la resolución de la Junta, así como al conde de Monterrey al que se le remitieron las cartas de estas para que las viese y también al cardenal Aldobrandini. La resolución final ${ }^{103}$ aceptaba el punto de la protección de Anna Carafa y "en ella entra también su Abuela y Estados", así como "lo que tiene y le pertenece en Sabioneda". Al duque de Medina de las Torres se le concedía la embajada a Roma con futura sucesión al virreinato na-

101.AGS, Estado, Nápoles, leg. 3332, doc. 89. Documento de la Junta, 21 de octubre de 1634.

102. Ibidem, doc. 90. Respuesta de Felipe IV a la Junta, 26 de octubre de 1634.

103. Para la resolución completa vide AGS, Estado, Nápoles, leg. 3332, doc. 110. 
politano, una renta por valor de Castilnuovo y, cuando entre en él, "otra tanta cantidad de encomiendas effectivas donde no del castillo" por la vida del duque y tres más para sus descendientes, y la futura sucesión del oficio de gran justiciero, cuando muriese el que actualmente lo poseía, para él y tres vidas más. Con estas decisiones puede decirse que la opinión del conde-duque había tenido gran influencia en el dictamen regio, ya que es precisamente su juicio el que aparece en el documento final en el punto más importante de la negociación, y en el único en el que su opinión era distinta a la de la mayoría, el virreinato.

Durante los primeros meses de 1635 se intercambiaron cartas sobre el asunto con el cardenal Borja ${ }^{104}$ y Monterrey, hasta la firma de los capítulos por parte de Anna y su madre en presencia del conde ${ }^{105}$, y estas escribieron $^{106}$ al monarca como agradecimiento y así también lo hizo el cardenal Aldobrandini ${ }^{107}$. Además, enviaron al conde Paulo Octavio Machirelli a fin de que diese fe de su agradecimiento personalmente en España.

La visita de Machirelli no fue únicamente un viaje de agradecimiento, sino que aprovechó para pedir sobre uno de los puntos con los que no habían quedado satisfechas, el del gobierno del reino de Nápoles, que solicitó para el duque de Medina por un periodo de seis meses. Al igual que durante las negociaciones anteriores, fue Alonso de la Carrera el que se mostró más favorable a la concesión del título de virrey -por ser solo seis meses de gobierno- aduciendo que "la conservación de la cassa de Stigliano no solo es interés particular sino público pues importa a la república que se conserve la dignidad y esplendor de las grandes casa y familias" ${ }^{108}$, así como que al ir el duque de Medina de las Torres como virrey, la princesa abuela "le recibiría por hijo" y no obraría en contra de su nieta. Asimismo, "se podría encaminar la reducción del duque de Parma al servicio de Vuestra Majestad" porque este es primo de la princesa, así como la "restitución de la plaça de Sabioneda"109. Esto suponía el problema de qué hacer con el conde de Monterrey, y don Alonso propuso que este pasase a Roma por este tiempo, aunque debían ser los Consejos de Estado y de Italia los que resolvieran el destino de Monterrey y la duración del virreinato de Medina.

104. AGS, Estado, Nápoles, leg. 3332, docs. 124, 126 y 127. Cartas y despachos al cardenal Borja.

105.Ibidem, doc. 129. Carta del conde de Monterrey a Felipe IV.

106. Ibidem, docs. 130-131. Cartas de Anna Carafa y Elena Aldobrandini a Felipe IV.

107. Ibidem, doc. 133. Carta del cardenal Aldobrandini a Felipe IV.

108. Ibidem, doc. 136. Parecer de don Alonso de la Carrera.

109. Ibidem. 
La aceptación de los capítulos por parte de Medina de las Torres se produjo, al menos oficialmente, el 21 de agosto de 1635, cuando pidió a Felipe IV que se le diesen los despachos de las mercedes que se le habían concedido y en la que daba cuenta de conocerlas y "tenerlo entendido y que no hay inconveniente" 110 . Unos días más tarde era Paulo Machirelli el que pedía respuesta ${ }^{111}$ para las cartas del cardenal Aldobrandini, la duquesa de Mondragón y la princesa Anna que le había presentado al rey.

Paulo Machirelli, durante su estancia en Madrid, tradujo al italiano para el duque de Medina de las Torres Continuazione della storia di Enrico IV, re di Francia e di Navarra ${ }^{112}$ de Pierre Matthieu, por orden del mismo duque de acuerdo con la dedicatoria ${ }^{113}$ escrita el 22 de octubre de 1635. En ella, además, le deseaba "un espedito imbarco, un Vento in poppa, un viaggio felice" ${ }^{114}$, por lo que la partida de Medina de las Torres parecía inminente. A pesar de esto, la princesa Isabella Gonzaga todavía no había aceptado el matrimonio de su nieta, por lo que finalmente la Junta ${ }^{115}$, a instancia de Paulo Machirelli, escribió el 9 de noviembre de 1635

He entendido que la plática de casamiento de vuestra nieta con el duque de Medina de las Torres se ha concluido y he holgado dello por lo bien que ha de estar a todos, teniendo por cierto que vos concurriréis también en esto con vuestra aprobación para que sea mayor el contento de que yo le tendré muy particular y creed que siempre miraré con muy buena volutad todo lo que fuere conveniencia y acrecentamiento de vuestra casa ${ }^{116}$.

Las cartas a la duquesa de Mondragón y su hija ${ }^{117}$, con un tono ligeramente distinto a esta, daban cuenta de la satisfacción en la conclusión de las negociaciones para el casamiento.

110. Ibidem, doc. 139. Del duque de Medina de las Torres a Felipe IV.

111. Ibidem, doc. 140. Carta de Paolo Machirelli, 29 de agosto de 1635.

112. P. Matthieu (s. f.), Continuazione della storia di Enrico IV, re di Francia e di Navarra, traducción en italiano de Paolo Machirelli. Biblioteca Nacional de España, MSS/2830.

113. Machirelli (s. f.), "Al Illmo et Eccmo; sigre; il Sr Duca di Medina dellas Torres", en P. Matthieu, Continuazione della storia di Enrico IV, re di Francia e di Navarra, traducción en italiano de Paulo Machirelli. BNE, MSS/2830, V.

114. Ibidem, VII

115. AGS, Estado, Nápoles, leg. 3332, doc. 145. Decisión de la Junta de escribir a Isabella Gonzaga, Madrid, 4 de noviembre de 1635.

116. Ibidem, doc. 147. Carta a Isabella Gonzaga, 9 de noviembre de 1635.

117. Ibidem, docs. 148-149. Cartas a Elena Aldobrandini y Anna Carafa, 15 de noviembre de 1635 . 


\section{EPÍLOGO}

Del estudio de la documentación producida por la Junta se extraen algunas ideas importantes. La primera de ellas es, efectivamente, el estado de las relaciones entre el conde-duque y del que había sido su "favorito" e "hijo", el duque de Medina de las Torres, en los años cruciales del valimiento de Olivares. La segunda es cómo la Corona gestionó las negociaciones de un matrimonio, en principio de interés particular, como una verdadera razón de Estado.

Como ya señaló Fiorelli, la relevancia patrimonial y las redes familiares de la princesa Anna, así como la proyección de su matrimonio, dan prueba de unas dinámicas que iban más allá de la propia nobleza napolitana ${ }^{118}$, y que puede entenderse como un interés de esta por estar en los círculos de poder de la monarquía. Esto también podría entenderse al revés, y es que la elección del duque de Medina de las Torres supuso un hecho mucho más complejo y de trascendencia mayor que el que hasta ahora se había creído, pues ya no es válida la hipótesis de que este fue elegido por ser hechura de Olivares, sino que es precisamente este matrimonio el que da pruebas del distanciamento entre ambos, al menos en este tiempo.

Por otro lado, la Corona, férrea en su posición respecto a la posesión de Sabbioneta y en los requisitos que debía tener el que pasase a ocuparla, también supo mostrarse "generosa" en las mercedes concedidas a la princesa, lo que da prueba de la capacidad gestora de la Monarquía, así como de sus principales intereses, al menos en este momento.

Por último, es importante señalar el papel del conde de Monterrey. De esta documentación se desprende que fue él el intermediario entre el rey y las Carafa en la proposición de Medina como candidato al matrimonio, sin informar, parece, al conde-duque del que también era hechura. Es conocida la enemistad entre Medina y Monterrey, por lo que podría haberse tratado de una maniobra para apartar al duque de la corte y minar su influencia dentro de la clientela de Olivares. Esta idea está reforzada por los hechos que sucedieron a la llegada del duque a Nápoles y que pusieron de relieve, con claridad, la rivalidad entre ambos, como ha estudiado A. Rivas ${ }^{119}$. Es posible que el conde de Monterrey no contase con la posibilidad de que los Carafa pidiesen como requisito que Medina de las Torres fuese virrey, 
lo que puso en riesgo la propia permanencia del conde en Nápoles, aunque esto solo se puede presentar como hipótesis ${ }^{120}$.

En conclusión, el estudio de este matrimonio revela nuevos planteamientos sobre el estado de la clientela de Olivares, en concreto, la relación entre el conde de Monterrey, el duque de Medina de las Torres y el conde-duque, así como la importancia de la nobleza italiana en los grandes proyectos de la Monarquía Hispánica, además de la importante capacidad de negociación de las mujeres como válidas interlocutoras en los asuntos familiares.

\section{BIBLIOGRAFÍA}

Affó, Ireneo (1780), Vita di Vespasiano Gonzaga duca di Sabbioneta, e Trajetto, Filippo Carmignani, Parma.

Aldimari, Biagio (1691), Historia genealogica della famiglia Carafa, Bulifon, Nápoles.

AMmirato, Scipione (1651), Delle famiglie nobili napoletane parte seconda, per Amadore Massi da Furlì, Firenze.

BouzA, Fernando (2009), "De Rafael a Ribera y de Nápoles a Madrid. Nuevos inventarios de la colección Medina de las Torres-Stigliano (1641-1656)", Boletín del Museo del Prado, 27, 2009, pp. 27-71.

Croce, Benedetto (1995), "Personajes de la historia italo-española. El duque de Nocera Francesco Carafa y Baltasar Gracián”, Cuaderno gris, 1, pp. 50-67.

Denunzio, Antonio Ernesto (2012), "Anna Carafa", en M. Mafrici (ed.), Alla corte napoletana. Donne e potere dall'età aragonese al viceregno austriaco (1442-1734), Liguori, Napoli, pp. 189-211.

- "Donna Anna Carafa, viceregina di Napoli: un palazzo a Posillipo e la memoria di una stirpe", en P. Belli (ed.), Palazzo Donn'Anna. Storia, arte e natura, Allemandi, Torino, pp. 19-38.

Elliott, Jonh Huxtable (2004), El conde-duque de Olivares, Austral, Barcelona.

Enciso Alonso-Muñumer, Isabel (2007), Nobleza, poder y mecenazgo en tiempos de Felipe III: Nápoles y el conde de Lemos, Actas, Madrid.

FIorelli, Vittoria (2008), "Una viceregina napoletana nella Napoli spagnola: Anna Carafa”, en L. Arcangeli e S. Peyronel (eds.), Donne di potere nel Rinascimento, Viella, Roma, pp. 445-462.

120. Villari opina que el conde de Monterrey "aveva accettato senza riserve (...) il disegno di sacrificare il Regno di Napoli alle esigenze belliche della monarchia". R. VILLARI (2012), 469. No obstante, en el momento de hacer la proposición del candidato por orden del rey a las princesas, esta posibilidad, probablemente, no se hubiera contemplado. 
Franganillo, Alejandra (2019), "Negociando con mujeres. Tensiones familiares e intereses políticos en torno a la sucesión del principado de Stigliano", en C. Sanz Ayán, S. Martínez Hernández, M. Aglietti y D. Edigati (eds.), Identità nobiliare tra monarchia ispanica e Italia. Lignaggi, potere e istituzioni (secoli XVI-XVIII), Biblioteca di Storia Sociale, 42, pp. 219-233.

Herrero SÁnchez, Manuel (s. a.), "Ramiro Núñez Felípez de Guzmán”, en Diccionario Biográfico Español, Real Academia de la Historia. URL: http://dbe.rah. es/biografias/14418/ramiro-nunez-felipez-de-guzman (consulta: 28/04/2020).

LABrot, Gerard (1995), Palazzi napoletani: storie di nobili e cortigiani 1520-1750, Electa Napoli, Napoli.

LABROT, Gerard (1979), Baroni in città: residenze e comportamenti dell'aristocrazia napoletana, 1530-1734, Società editrice napoletana, Napoli.

Lucci, Laura (1905), Donn'Anna Carafa, Tip. Luigi Fierro e figlio, Napoli.

Marañón, Gregorio (1958), El conde-duque de Olivares, Espasa-Calpe, Madrid (10. ${ }^{\mathrm{a}}$ ed.). Primera edición: 1936.

Marhuenda, Francisco (2019), "La prodigalidad en la concesión de títulos", en F. Barrios Pintado y J. Alvarado (dirs.), Aires de grandeza: Hidalgos presuntos y Nobles de fantasía, RAH y Dykinson, Madrid.

Minichini, Benedetto (1860), Del cognome e dello scudo dei Carafa nobili napoletani, Stabilimento tipografico del Cav. Gaetano Nobile, Napoli.

PIsAni, Massimo (1992), I Carafa di Roccella: storie di principi, cardinali, gradi dimore, Electa, Napoli.

Reumont, Alfred von (1854), The Carafas of Maddaloni: Naples under Spanish dominion, Henry G. Bohn, London.

Rivas Albaladejo, Ángel (2015), Entre Madrid, Roma y Nápoles. El VI conde de Monterrey y el gobierno de la Monarquía Hispánica (1621-1653), Universitat de Barcelona. Tesis doctoral.

Sabatini, Gaetano y Dandolo, Francesco Carlo (2012), El estado feudal de los Carafa de Maddaloni: origen y administración de un ducado en el reino de Nápoles (siglos XV-XVIII), Prohistoria, Rosario (Argentina).

SÁNCHEZ GARCíA, Encarnación (2017a), “«Aplicossi a render inmortale la sua memoria nel Regno». El virrey Medina de las Torres en Nápoles (1636-1644)”, en A. Carrasco (ed.), La nobleza y los reinos. Anatomía del poder en la Monarquía de España (siglos XVI-XVII), Iberoamericana/Vervuert, Madrid.

- (2017b), "Il vicerè Medina de las Torres a Napoli: decoro del lignaggio e avanguardia culturale", en P. Belli (ed.), Palazzo Donn'Anna. Storia, arte e natura, Allemandi, Torino, pp. 39-69.

SodAno, Giulio (2018), "Le aristocrazie napoletane ai tempi di Filippo IV", en J. Martínez Millán, R. GonzÁlez Cuerva y M. Rivero Rodríguez (dirs.), La Corte de Felipe IV (1621-1665): reconfiguración de la Monarquía católica, tomo IV: Los Reinos y la política internacional, vol. 3, coord. por G. Tore, A. Musi, G. Murgia y R. Cancila, Polifemo, Madrid, pp. 1335-1380. 
"No permita vuestra Majestad que yo reciba daño...

SPAgnoletti, Angelantonio (2003), Le dinastie italiane nella prima età moderna, Il Mulino, Bologna.

Spagnoletti, Angelantonio (1996), Prìncipi italiani e Spagna nell'età barocca, Bruno Mondadori, Milano.

St. John, Horace Roscoe (1872), The court of Anna Carafa, Tinsley Brothers, London.

Strandling, Robert A. (1988), Philip IV and the government of Spain, 1621-1665, University Press, Cambridge.

Suárez de Alarcón y Mendoza, Antonio (1665), Commentarios de los hechos del Senor Alarcon, Marques de Valle Siciliana de Renda, y de las guerras en que se halló por espacio de cincuenta y ocho años, Diego Díaz de la Carrera, Madrid.

TARsia, Paolo Antonio de (1670), Tumultos de la ciudad y reyno de Napoles en el año de 1647, Claudio Burgea, Lyon.

Viceconte, Filomena (2013), Il duca de Medina de las Torres (1600-1668) tra Napoli e Madrid: mecenatismo artistico e decadenza della monarchia, Universitat de Barcelona. Tesis doctoral.

Villari, Rosario (2012), Un sogno di libertà. Napoli nel declino di un impero. 1585-1648, Mondadori, Milán, 2012 [ebook].

Visceglia, Maria Antonietta (1988), Il bisogno di eternità. I comportamenti aristocratici a Napoli in età moderna, Guida, Napoli. 